\title{
Sexual coercion: Young men's experiences as victims and perpetrators
}

\author{
Deepika Ganju \\ Population Council \\ William Finger \\ Shireen J. Jejeebhoy \\ Population Council \\ Vijaya Nidadavolu \\ K.G. Santhya \\ Population Council
}

See next page for additional authors

Follow this and additional works at: https://knowledgecommons.popcouncil.org/departments_sbsr-pgy

Part of the Family, Life Course, and Society Commons, Gender and Sexuality Commons, and the International Public Health Commons

How does access to this work benefit you? Let us know!

\section{Recommended Citation}

Ganju, Deepika, William Finger, Shireen J. Jejeebhoy, Vijaya Nidadavolu, K.G. Santhya, Iqbal Shah, Shyam Thapa, and Ina Warriner. 2004. "Sexual coercion: Young men's experiences as victims and perpetrators," research brief. New Delhi: Population Council. 


\section{Authors}

Deepika Ganju, William Finger, Shireen J. Jejeebhoy, Vijaya Nidadavolu, K.G. Santhya, Iqbal Shah, Shyam Thapa, and Ina Warriner 


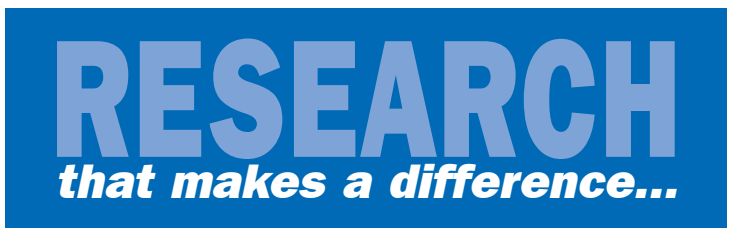

\section{SEXUAL COERCION: Young men's experiences as victims and perpetrators}

Available evidence suggests that a considerable number of young people experience nonconsensual sex across the world. However research has mainly concentrated on the experiences of young girls and their perspectives of perpetrators of violence. Little is known about coercion among young males as victims or perpetrators.

Case studies presented at an international consultative meeting in September 2003 in New Delhi challenged the common assumption that only women are victims of violence, and shed light on the experiences of young males as victims of sexual coercion (see box inside). These case studies for the first time also discussed the perspectives of young males as perpetrators of violence against young women.

The evidence comes from small-scale studies from Goa, India; Ibadan, Nigeria; Leon, Nicaragua; Mexico City, Mexico; Phnom Penh, Cambodia and selected settings in Peru and South Africa. ${ }^{1}$ The findings therefore are instructive but not representative. Common themes drawn from these diverse studies and key issues are discussed in this brief.

\section{Young males as victims of coercion}

\section{Forms of coercion}

Young men, like women, report experiencing a variety of coercive behaviours, ranging from unwanted touch, verbal abuse, unwanted kiss and deception that sets the stage for coercion to the use of violent force. In many settings, rape and other physically violent behaviours are not isolated events but typically follow a series of attempts to persuade or coerce the victim through verbal harassment or unwanted touch to engage in sexual relations.
A recent review of the literature on non-consensual sex reveals that a number of boys and young men (up to 10 per cent of the populations studied) experienced forced sexual relations in a variety of contexts. ${ }^{2}$ In South Africa, for example, men's experiences of early sexual abuse ranged from unwanted sexual touch, to being made to touch someone sexually, to having penetrative sex. Schoolgoing adolescent males in India reported high rates of sexual abuse including being touched without permission, private parts being brushed or being forced to have sex. Among young sexually experienced males in Peru, many had experienced sexual coercion, and a significant minority reported coercive sexual initiation. Men in Nicaragua also reported experiencing early sexual abuse, including penetrative sex. ${ }^{3}$

\section{Perpetrators of violence}

For the most part, perpetrators of violence on young male victims are males, and are known persons not strangers. In most cases, perpetrators are peers but occasionally older men as well. In Peru, for example, the majority of young men reported forced sex with steady or casual male partners, or male relatives. In South Africa, too, a significant minority of young men reported being forced to have sex with other men. Among schoolboys in India, the most common male perpetrators were older students or friends. In Nicaragua, perpetrators were primarily male family members or known males. ${ }^{4}$

A smaller number of young men reported sexual coercion by females. A range of perpetrators were mentioned, including intimate partners and sexually experienced women. In Nigeria for example, young men reported that girlfriends pressurized them to have sex. Subtle forms of coercion were used, including undressing, touching or commenting on the young male's penis, or taunting his lack of virility. 


\section{Sexual coercion: Young men's experiences as victims and perpetrators}

In some settings, such as Mexico, young men reported unwanted sex with sexually experienced women. In South Africa young males were pressurized by older women ("sugar mommies") to have sex against their wishes. Transactional sex was also reported in some settings, where gifts and money were exchanged for forced sexual favours. ${ }^{5}$

As highlighted in a study in Mexico, interpretations of sexual experiences by young males may differ depending on the sex of the perpetrator. Where the perpetrator is a male, forced sex is likely to be reported as a coercive experience or rape. In contrast, when the perpetrator is a female, most males regarded the incident far less seriously- more as "pressure" to have unwanted sex rather than rape, and some men even reconstructed such experiences as pleasurable. Young male victims seldom regarded women as being the sexual aggressor in incidents of unwanted sex, perhaps because this would threaten the masculinity of the victim. ${ }^{6}$

\section{Consequences of coercion}

Little is known about the consequences of forced sex for male victims. Psychosocial consequences have however been reported in a number of settings; by and large these refer to victims of coercion by males rather than females. In India, young men who had experienced coercive sex reported a range of adverse psychosocial consequences, including poor mental health and suicidal ideation. Similarly, young men in Nicaragua experienced significantly higher risks of suicidal ideation and behaviour as compared to those who had consensual sexual relations. ${ }^{7}$

Forced sex can also result in anxiety among victims regarding their masculinity. In Peru, for example, rape by a male is perceived by peers to have feminized the victim, as it is commonly believed that victims find the experience pleasurable — "when the boy is touched by a man, he becomes a queer". In Mexico, men who experienced forced coital initiation with sexually experienced women also reported anxiety and negative emotional outcomes, as these experiences did not fit the stereotype of masculine behaviour of being sexually controlling and dominant. ${ }^{9}$ Evidence also suggests that young males who were exposed to early coercive sex experienced significantly higher subsequent exposure to other forms of violence and abuse compared to others. ${ }^{10}$

Many studies suggest that sexual abuse among young men is associated with a "culture of silence" and inaction is a common response. Young males seldom sought medical care or judicial redress because of stigma or self-blame, or fears about their masculinity. Consequently, victims suffered in silence while perpetrators were seldom punished. ${ }^{11}$

\section{Young men as perpetrators of violence against women}

There is negligible information on men as perpetrators of violence against men. However, at the New Delhi meeting, evidence was presented on the perspectives and attitudes of men as perpetrators of violence against women.

\section{Forms of violence against women}

Various forms of coercion by males were reported. Physical forms of violence were used as well as more subtle forms of coercion such as verbal persuasion, blackmail or trickery to force women to have unwanted sex. Men forced sexual encounters either singly or in groups, and victims included girlfriends, intimate partners, sex workers or strangers. Some encounters were perpetrated under the influence of alcohol or drugs. Coercion was often reported in transactional sex. ${ }^{12}$

Studies disclose that young men in various settings such as Nigeria, South Africa, Peru and Mexico often force sex with known females, such as intimate or casual partners in dating relationships. ${ }^{13}$

New research reveals that a phenomenon that is emerging in several settings is gang rape. A significant proportion of young males in South Africa, Peru and Cambodia reported participating in forced sex in large groups or knowing other men who had participated in such encounters. By and large, these incidents of coercion are accompanied by physical force or the threat of physical violence. In most settings, rape is perceived by the perpetrator to be an act of affirmation of masculinity. ${ }^{14}$

In South Africa, "streamlining" or gang rape was reported by young men usually to "punish" their girlfriends for perceived infidelity. Men also reported gang-raping non-intimate partners such as drunken women in bars, girls perceived to be virgins, or women who are perceived as challenging men's dominant role in society. Streamlining appears to be a common occurrence and many young men had participated in streamlining before they were 18 years old. ${ }^{15}$ 
In Cambodia, too, male students reported participating in gang rape, colloquially known as bauk, where several young men have coercive sex with a woman. The victim is often a sex worker or a student perceived as sexually available, but rarely an intimate partner. Threats of physical violence are common during bauk, sometimes accompanied by actual physical force. Young men in Peru, too, reported group rape of women, sometimes with girls under the effect of alcohol or drugs. ${ }^{16}$

Gang rape is perceived as a way of group bonding and is subject to considerable peer pressure. In Cambodia, for example, young men said that they participated in gang rape "because we need sex and want to have fun together". Some reported that although they knew that gang rape was unacceptable, they were forced by their friends to participate. In Nigeria, friends not only abetted, but also participated, in the rape. ${ }^{17}$

Where sexual initiation for perpetrators involves the use of force, it could set a precedent to use sexual violence in future sexual encounters.

\section{Perceptions of entitlement to forced sex}

Common reasons for instigating coercion emerge from the experiences of different countries. A major reason for the social acceptance of violence by males is because societies impose significant double standards on the sexual behaviour of men and women, particularly during adolescence. In Cambodia, for instance, young girls are expected to uphold the honour of their family by maintaining their reputation and preserving their virginity. Young men, in contrast, are often expected to seek out multiple partners, both prior to and after marriage, because it is commonly perceived that their "irrepressible sexual needs must be met". According to young male students in Cambodia, for example, "I don't think it [bauk] is good, but at that time my passion is too strong." ${ }^{18}$ In fact, it is widely believed that once sexually aroused, men are unable to control themselves and should be provided with sex as a "right". Consequently, in many settings such as in South Africa, acts of sexual coercion are considered normal boyish behaviour and men are not blamed for forcing sex. ${ }^{19}$

Societal and gender norms shape young persons' attitudes to coercive sex, and are often used to justify such actions. Indeed, the use of force by young men and adolescent boys on women in some settings may even be considered "normative" behaviour. Young males in Nigeria, for example, legitimized rape as a way of teaching an unwilling female a lesson or punishing a woman for spurning their advances. Coercion was considered a weapon to punish an "arrogant" girl for refusing to accede to a man's request for friendship or sex. Violence against women was justified if the woman was being "difficult" and did not want to have sex..$^{20}$ In Cambodia, young men considered it acceptable to force women who were perceived as sexually available into having sex, stating that: "I have never experienced bauk with a good girl". ${ }^{21}$

Many young men felt a sense of entitlement to force sex on girlfriends or women on whom they had spent money or given gifts. For example, in Cambodia, adolescent boys stated: "If she does not follow [my desire], I'll beat her because I have the money to pay for sex". The lack of willing sexual partners and financial resources to purchase sex were also reported as factors motivating the use of force. ${ }^{22}$

Such coercive behaviours appear to have social acceptance among young women as well. In settings such as South Africa and Peru, both girls and boys felt that the victim was responsible for the perpetration of forced sex and may have even provoked the incident. ${ }^{23}$ Women in Nigeria believed that once a girl agrees to be a girlfriend she should be available for sex. Many girls acceded to a boy's request for friendship or sex for fear of violence or sexual abuse. ${ }^{24}$

Young men who perpetrated coerced sex believe that a woman does not have the right to control her own body and that non-consensual sex is not an infringement of basic human rights. In many cases coercive behaviours are not challenged and there is little social pressure from parents, families and society to discourage young men from engaging in such acts.

\section{Summing up}

These studies on forced sex from the perspective of male victims and perpetrators are pioneering efforts that provide an insight on the subject. However, given the sensitivity of the issue and the reluctance of young male victims to seek redress, studies on the subject are few and sample sizes

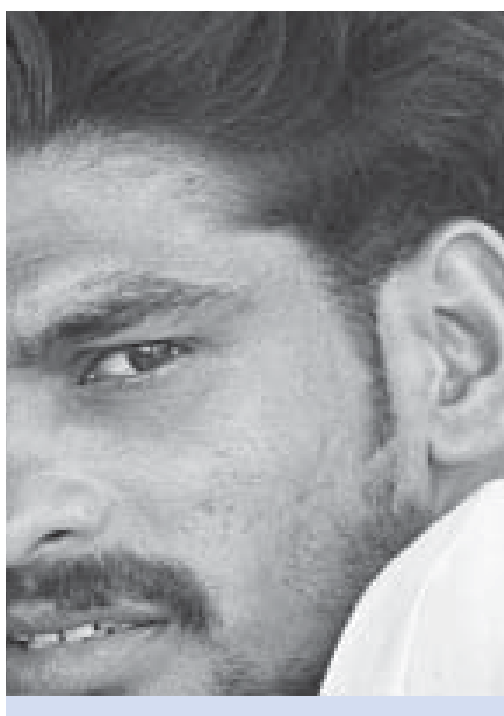

Global consultative meeting on nonconsensual sex among young people

In September 2003, a global consultative meeting on nonconsensual sex among young people in developing countries was held in New Delhi, India. The meeting was organized by Population Council in collaboration with World Health Organization/Department of Reproductive Health and Research, and Family Health International/YouthNet. Participants included researchers, legal analysts, representatives from community-based NGOs, policy makers, and young people themselves.

Sessions examined the following issues in relation to non-consensual sex: experiences of young females and males: prevalence, forms and contexts; youth perspectives, through a panel of seven youth; patterns of transactional sex; roles of the legal system; outcomes of coercion at the individual and community level; interventions to prevent non-consensual sex, and to support and treat victims; and research design and methods. 
small. Although studies have been conducted in diverse settings, common trends are evident which suggest that the extent of the problem is far greater than perceived and several issues require to be urgently addressed.

The main findings that emerged at the meeting were:

\section{- Contrary to common perceptions, a} considerable percentage of young men also experience sexual coercion.

- Young male victims tend to suffer in silence and are reluctant to share experiences of coercion with their peers or others in the community.

- Few victims seek legal redress.

- Adverse health and psychosocial consequences of sexual abuse for male victims include an increase in the incidence of sexually transmitted infection, anxiety about their sexual orientation and a crisis of their masculine identity. Young male victims are vulnerable to subsequent violence.

- A significant number of young men reportedly perpetrate rape, mostly on young girls. Presumably, many more perpetrate such acts as unwanted touch, verbal abuse and unwanted kiss.

- Gang rape of young women by young males is reported in several settings.

- Young males feel a sense of entitlement to force sex. In some cultures, gang rape is viewed as an affirmation of their masculinity and group bonds, and is often characterized by considerable peer pressure.

- The use of force is often condoned by males and females, and is rarely challenged by parents or the community.

\section{Recommendations for action}

We need to know more about the prevalence of non-consensual relations among young men and the context in which violence is perpetrated. Several challenges remain and many questions are unanswered: What is the nature of coercion by men and women that young men experience? Who are the perpetrators? What are the perspectives and attitudes of young men as perpetrators of violence against men as well as women? How is violence transmitted through social networks and from generation to generation? And how can gender norms that perpetuate coercion among young men and justify the use of force by male perpetrators be challenged?

Future action should be directed to:

- Strengthening young people's understanding of human rights in the context of the right of young men and women to control their own bodies.

- Promoting negotiating skills among young boys and girls.

- Making parents aware of the importance of communicating with youth on sexual matters.

- Using role models to stimulate positive behaviour change.

- Orienting teachers and health service providers to be supportive and non-judgemental.

- Providing education and counselling services that will equip young people with the necessary awareness and skills to protect themselves and seek appropriate care.

- Ensuring a stronger legal and regulatory environment that will be a deterrent to perpetrators.

- $\quad$ Sensitizing young men to question prevailing norms that equate masculinity with forced sex.

- Stimulating a broader debate on these issues through the media.
Population Council

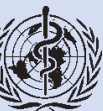

World Health Organization

\section{YsuthNet}

For further information please contact: Population Council

Zone 5A, India Habitat Centre Lodi Road, New Delhi - 110003

Ph.: +91 $1124642901 / 2$

Fax: +91 1124642903

email: info@pcindia.org

www.popcouncil.org

Deepika Ganju, in collaboration with Shireen Jejeebhoy, Vijaya Nidadavolu and K.G. Santhya (Population Council); William Finger and Shyam Thapa (Family Health International/ YouthNet); and lqbal Shah and Ina Warriner (World Health Organization/ Reproductive Health and Research).

\section{References}

References to presentations from Non-consensual Sexual Experiences of Young People in Developing Countries: A Consultative Meeting, New Delhi, India, September 22-25, 2003 are noted as New Delhi meeting.

1 Ajuwon, A., Research in sexual coercion among young persons: The experiences and lessons learned from Ibadan, Nigeria, New Delhi meeting; Caceres, C., The complexity of young people's experiences of sexual coercion: Lessons learned from studies in Peru, New Delhi meeting; Ellsberg, M., Coerced sex among adolescents in Latin America and the Caribbean, New Delhi meeting; Jewkes, R., Non-consensual sex among South African youth: Prevalence of coerced sex and discourses of control and desire, New Delhi meeting; Marston, C., Pitfalls in the study of sexual coercion: What are we measuring and why? New Delhi meeting; Patel, V., The prevalence and correlates of sexual abuse among school-based adolescents in Goa, New Delhi meeting; Wilkinson, J.W., L.S. Bearup and T. Soprach, Youth gang-rape in Phnom Penh, New Delhi meeting.

2 Jejeebhoy, S.J. and S. Bott. 2003. Non-consensual sexual experiences of young people: A review of the evidence from developing countries. Population Council Working Paper No. 16, New Delhi.

3 Caceres, New Delhi meeting; Ellsberg, New Delhi meeting; Jewkes, New Delhi meeting; Patel, New Delhi meeting.

4 Caceres, New Delhi meeting; Ellsberg, New Delhi meeting; Jewkes, New Delhi meeting; Patel, New Delhi meeting.

5 Ajuwon, New Delhi meeting; Jejeebhoy and Bott, 2003; Jewkes, New Delhi meeting; Marston, New Delhi meeting.

6 Marston, New Delhi meeting.

7 Ellsberg, New Delhi meeting; Patel, New Delhi meeting.

8 Caceres, New Delhi meeting.

9 Marston, New Delhi meeting.

10 Jejeebhoy and Bott, 2003.

11 Caceres, New Delhi meeting; Patel, New Delhi meeting.

12 Jejeebhoy and Bott, 2003.
13 Ajuwon, New Delhi meeting; Caceres, New Delhi meeting; Jewkes, New Delhi meeting; Wilkinson, Bearup and Soprach, New Delhi meeting.

14 Caceres, New Delhi meeting; Jewkes, New Delhi meeting; Wilkinson, Bearup and Soprach, New Delhi meeting.

15 Jewkes, New Delhi meeting.

16 Caceres, New Delhi meeting; Wilkinson, Bearup and Soprach, New Delhi meeting.

17 Ajuwon, New Delhi meeting; Wilkinson, Bearup and Soprach, New Delhi meeting.

18 Wilkinson, Bearup and Soprach, New Delhi meeting.

19 Jewkes, New Delhi meeting.

20 Ajuwon, New Delhi meeting.

21 Wilkinson, Bearup and Soprach, New Delhi meeting.

22 Wilkinson, Bearup and Soprach, New Delhi meeting.

23 Caceres, New Delhi meeting; Jewkes, New Delhi meeting.

24 Ajuwon, New Delhi meeting. 